\title{
Commentary: My access is your access
}

\author{
Stefanos Demertzis, MD
}

\footnotetext{
From the Department of Cardiac Surgery, Cardiocentro Ticino, Lugano, Switzerland; Faculty of Medicine, University of Bern, Bern, Switzerland; and Faculty of Biomedical Sciences, Università della Svizzera Italiana, Lugano, Switzerland.

Disclosures: Author has nothing to disclose with regard to commercial support.

Received for publication Feb 28, 2019; accepted for publication Feb 28, 2019; available ahead of print April 5, 2019.

Address for reprints: Stefanos Demertzis, MD, Department of Cardiac Surgery, Cardiocentro Ticino, Via Tesserete 48, CH-6900 Lugano, Switzerland (E-mail: demertzis@ cardiocentro.org).

J Thorac Cardiovasc Surg 2019;158:1367

$0022-5223 / \$ 36.00$

Copyright (C) 2019 by The American Association for Thoracic Surgery

https://doi.org/10.1016/j.jtcvs.2019.02.104
}

Patients in profound cardiogenic shock in a cath lab can require life-saving extracorporeal assistance. We gain arterial and venous access for cannulation usually through the groin vessels by surgical exposure or percutaneously (sometimes transforming the arterial access intended for the catheterization). There are situations in which establishing a second arterial access for the catheterization can be challenging and time-consuming. This can happen because of pulseless circulation and/or anatomic characteristics (eg, calcified vessels or hematomas from prior puncture attempts). Pasrija and colleagues ${ }^{1}$ present an ingenious connector, placed between the arterial cannula and the tubing, that enables insertion and manipulation of a catheter (5F-7F). The idea is brilliant, simple, and despite seeming obvious it is surprisingly new and the study delivers a proof of concept with working prototypes. After a closer look, questions arise: How would a catheter within an arterial cannula influence flow and cannula characteristics? The authors showed in a basic in vitro and animal study that the catheter did not alter perfusion and cannula characteristics significantly. They also demonstrated accessibility of the coronary system by the catheters inserted through the new connector. For more sophisticated interventions than a straightforward percutaneous transluminal coronary angioplasty of a culprit lesion, other issues have to be addressed, such as the maneuverability and position stability of the catheter within the high-pressure, high-flow cannula or thrombus formation at the connector. Access through the connector could be also used for other catheters, such as a balloon pump. Obviously the connector could serve as an

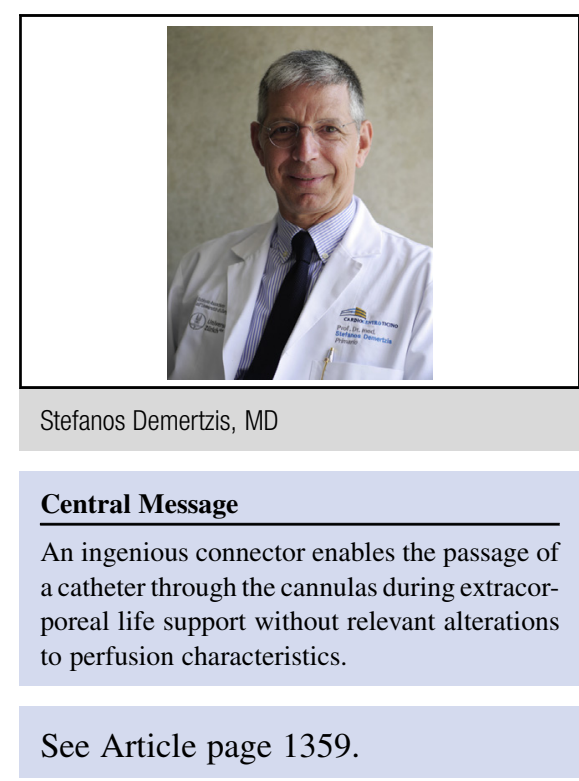

additional venous access port. This invention could optimize treatment and care for critically ill patients, sparing them from the potential complications of a second arterial access under difficult conditions and its closure after the procedure under full anticoagulation and double antiplatelet therapy.

I hope this smart invention will be followed through by the authors and picked up by industry. Potential safety issues in the high-pressure environment just before the cannula, especially for longer indwelling periods, have to be addressed.

Surgeons have an almost obsessive protection instinct toward cannulas. In this context, we should offer access to our cannulas for patients' benefit.

\section{Reference}

1. Pasrija C, Bittle GJ, Zhang J, Morales D, Tran D, Deatrick KB, et al. A novel adaptor system enables endovascular access through extracorporeal life support circuits. J Thorac Cardiovasc Surg. 2019;158:1359-66. 